\title{
Effects of social media use on desire for cosmetic surgery among young women
}

\author{
Candice E. Walker ${ }^{1} \cdot$ Eva G. Krumhuber ${ }^{1} \cdot$ Steven Dayan $^{2} \cdot$ Adrian Furnham $^{3}$ \\ Published online: 30 April 2019 \\ (C) The Author(s) 2019
}

\begin{abstract}
A large body of research has documented the influence of traditional media formats (e.g. television programs, adverts) on young women's consideration of cosmetic surgery. However, less is known about how newer forms of media such as social networking sites impact desire for cosmetic surgery. The present study aimed to examine whether exposure to images depicting facial cosmetic enhancements increases the desire for cosmetic surgery among young women. One-hundred and eighteen women, aged 18-29 years, indicated their social media use. This was followed by a task in which they viewed either images of facial cosmetic enhancements $(N=59)$ or images of travel $(N=59)$. Participants then indicated their satisfaction with their appearance, their mood and desire to undergo cosmetic enhancement. The results showed that viewing images of females who have undergone cosmetic enhancements affected young women's desire for cosmetic surgery, especially if they spent a significant amount of time on social media, followed many accounts, and were less satisfied with their appearance. These findings have implications for parents, clinicians, and policy makers for understanding how internet habits, particularly the use of social media, influence the desire for cosmetic surgery, including the psychosocial motivations underlying those intentions.
\end{abstract}

Keywords Body image $\cdot$ Cosmetic surgery $\cdot$ Social media $\cdot$ Instagram $\cdot$ Between-subjects

\section{Introduction}

Physical appearance is an important aspect of personal identity and its relation to individuals' self-perception begins early in life (Davison and Birch 2001). Although perceptions of attractiveness are guided by innate preferences such as symmetry and small waist-to-hip ratio among women (Swami and Furnham 2008), the socio-cultural environment can also influence perceptions of attractiveness (Cafri et al. 2005). The Tripartite Influence Model (Thompson et al. 1999) argues that beauty ideals are reinforced and transmitted by three primary sociocultural influences: peers, parents, and the media. These influences are mediated by two factors, namely internalisation of appearance ideals and appearance comparison. Internalisation occurs when a person has accepted societies'

Eva G. Krumhuber

e.krumhuber@ucl.ac.uk

1 Department of Experimental Psychology, University College London, 26 Bedford Way, London WC1H 0AP, UK

2 University of Illinois, Champaign, IL, USA

3 University College London, London, UK beauty ideals and engages in behaviours to achieve that ideal. Appearance comparison relates to people evaluating and directly comparing themselves to others based on how they look. It is proposed that if a person internalizes beauty ideals about appearances (i.e. those depicted by the media or reinforced by parents) that s/he cannot live up to and/or habitually engages in appearance comparison (e.g. with peers), this can create problems with body image such as body dissatisfaction (Thompson et al. 1999). The media exerts a strong influence on societies' ideas about body image i.e. what body-type one should have, what one should wear, primarily through the conveyance of messages focused on the 'ideal body' in magazines, newspapers and TV. Whilst the effects of media messages on women's body image have been examined using various forms of traditional media, including television and magazines (Groesz et al. 2002), less is known about how newer forms, such as social media, influence their perceptions.

\section{The Influence of Social Media on Body Image}

In today's society the importance of physical appearance as dictated by the media is arguably more persuasive than ever, especially among younger people and through newer forms of media such as Social Networking Sites (SNS) (Fardouly and 
Vartanian 2016). Instagram is a free social networking platform, allowing users to edit and share photos and videos through a mobile app. In comparison to other SNS, such as Facebook and Twitter, Instagram revolves around images and less so on the written text. The visual, picture-orientated nature of SNS, especially Instagram, encourages users to view and comment on the pictures that other users display on their profiles (Pempek et al. 2009). One's physical appearance can play an important role in whether other users look at and comment on these pictures. For example, Ringrose (2011) found that British teenage girls reported that they frequently received comments about their physical attractiveness through their social media profile. Hence, how we are perceived on SNS can influence the perception of our appearance and, in some instances, may encourage people to want to do something about it (De Vries et al. 2014). For example, people may engage in low-level appearance change, such as dying their hair, altering the clothes they wear or changing how they apply their make-up. In other instances, the changes may be more long-lasting and dramatic, such as those brought about by cosmetic enhancements. In such cases, these changes can have severe consequences for their psycho-physical functioning as the physical changes may influence their well-being for better or worse (Castle et al. 2002).

Social media use is widespread across Britain and is a pervasive aspect of young adults' daily lives. The Office for National Statistics (2017) found that the most popular use of the internet for adults aged 16-24 years (96\%) and 2534 years (88\%) is social networking. However, the ubiquitous influence of social media is not always positive. Increased social media use has been related to more body image concerns and eating disorders (Holland and Tiggemann 2016). Other research has suggested that Instagram is one of the most detrimental social media platforms for young people's mental health and wellbeing (The Royal Society for Public Health 2017). Similarly, a study by Brown and Tiggemann (2016) found that viewing pictures of attractive celebrities and peers on Instagram has a negative effect on women's mood and body image. Together, these findings would suggest that high usage of SNS, especially picture-based ones, can be harmful for certain individuals in regard to their body image and psychosocial functioning, such as lowered self-esteem and increased risk of depression and anxiety (Brown and Tiggemann 2016; Holland and Tiggemann 2016; The Royal Society for Public Health 2017).

In line with the increasing trend in social media use, there is also an increasing number of young people having cosmetic procedures, reportedly rising from $17.2 \%$ in 2014 to $18.2 \%$ in 2017 (American Society for Aesthetic Plastic Surgery 2017). Cosmetic surgery involves the "maintenance, restoration or enhancement of one's physical appearance through surgical and medical techniques" (Swami et al. 2009, p. 1). Cosmetic surgery differs from reconstructive surgery in that the latter is a surgical procedure done to restore function or normal appearance. It is often performed on abnormal structures of the body such as those caused by trauma or infection. In contrast, cosmetic surgery is performed on normal structures of the body and is usually done to improve appearance and form (American Society of Plastic Surgeons 2018). Cosmetic surgery has become an increasingly popular means of enhancing one's appearance, with around 30,000 procedures being carried out last year according to the British Association for Aesthetic Plastic Surgeons (2017), and is an industry that is heavily influenced by 'popular culture'. For example, the American Academy of Facial Plastic and Reconstructive Surgery (2013) reported an increase in requests for surgery as a result of social media photo sharing. Of the procedures mostly likely to be requested as a result of social media influence were rhinoplasty, Botox and facelifts, suggesting that young people may be influenced to undergo cosmetic procedures by what they see online. Similarly, a study has shown that among cosmetic surgery patients, Facebook, YouTube and Instagram are high in use and engagement for information regarding procedures, such as practice information, before and-after photographs, and contests (Sorice et al. 2017). However, despite the growing popularity in cosmetic procedures, the social and psychological factors that influence attitudes towards cosmetic surgery are yet to be fully explored.

\section{Predictors of the Desire to Undergo Cosmetic Surgery}

There are several factors that have been reported to predict an individual's desire to undergo cosmetic surgery. Consistently, body dissatisfaction has been shown to be a key motivational factor for cosmetic surgery among both women and men (Pertschuk et al. 1998; Sharp 2018). Body dissatisfaction relates to the negative thoughts that an individual has about their body. It involves feelings of discrepancy between the actual body shape and an ideal one (Grogan 2008). Markey and Markey (2009) found that out of physical appearance, teasing and media influence, body dissatisfaction was the best predictor of interest in undergoing cosmetic surgery. On the contrary, young women who were satisfied with their bodies were the least likely to desire bodily change (Lee et al. 2009). It may be that body dissatisfaction acts as a mediator between young women's perceptions of their bodies and attempts to change them. As such, women who negatively perceive themselves may become dissatisfied with their appearance which in turn makes them express a greater desire for engaging in appearance-changing strategies such as cosmetic surgery (Markey and Markey 2005).

Additionally, self-esteem has been shown to be related to the likelihood of undergoing cosmetic surgery, with those who have lower self-esteem being significantly more likely to want to have cosmetic procedures (Furnham and Levitas 2012). Self-esteem can be classified as the extent to which 
individuals value and accept themselves and think favourably of themselves (Blascovich and Tomaka 1991). Relatedly, selfesteem has been found to significantly increase in some individuals as a result of undergoing cosmetic surgery (Soest et al. 2009), suggesting that their low-self-esteem functions as a motivating factor for decisions in the first place. Weight and diet are also found to be related to the motivation to have cosmetic surgery. For example, heavier women desire more cosmetic procedures (Henderson-King and Brooks 2009). Conversely, a study looking at female university students found that a low BMI predicted a greater consideration of cosmetic surgery (Swami 2009). As such, there may be an increased motivation for cosmetic surgery at either extremes of the BMI scale. Moreover, Body Dysmorphic Disorder (BDD) has consistently been found to be related to the desire to undergo cosmetic surgery. Among individuals who seek cosmetic enhancements it is estimated that $7 \%$ to $15 \%$ have the condition (Crerand et al. 2006). Individuals with BDD have a preoccupation with an imagined or minimal defect in their appearance (American Psychiatric Association 2013). Appearance-changing strategies such as cosmetic surgery are then often conceived as a way to get rid of this perceived defect. Paradoxically, individuals with BDD who engage in cosmetic surgery as a way to treat their BDD often display significantly negative outcomes, such as being dissatisfied with the result of the surgery, exhibiting higher levels of psychopathology and low self-esteem (Mulkens et al. 2012). As cosmetic treatments rarely resolve the symptoms of BDD and in some cases can make symptoms worse (Mulkens et al. 2012), the evaluation of the psychological condition and motivation of the patient in cosmetic treatment options is imperative.

In addition, the social environment has a significant influence on individuals' desire to have cosmetic surgery. Here, experiences of bullying and teasing are motivating factors for people to undertake cosmetic surgery and to fix their body dissatisfaction. Teased individuals also report lower levels of physical attractiveness and appearance satisfaction and higher levels of anxiety and depression (Jackson et al. 2012). This applies in particular to women with a history of teasing which makes them more likely to have cosmetic surgery (Soest et al. 2006). Also, the extent to which cosmetic surgery is socially accepted exerts an impact on the motivation for cosmetic surgery. Hearing about other people's experiences of cosmetic surgery increases the likelihood of individuals indicating that they would undergo a cosmetic procedure (Brown et al. 2007) and patients who have undergone cosmetic procedures consistently report knowing someone who has had cosmetic surgery (Javo and Sørlie 2010; Solvi et al. 2010).

Furthermore, the media has a well-documented influence on desire for cosmetic surgery. Sociocultural theory suggests that people learn beauty standards within the social and cultural context (Thompson et al. 1999). People judge their own appearance based on the beauty standards defined by the society in which they live. The media is one channel through which messages about beauty ideals are portrayed (Cafri et al. 2005) and has an effect on how women perceive themselves and thus whether they engage in appearance-changing strategies. For example, greater psychological investment in physical appearance and greater internalisation of mass media messages of beauty are found to predict more favourable attitudes towards cosmetic surgery (Sarwer et al. 2005). Similarly, media (cosmetic surgery-related and appearance- related television programmes and cosmetic surgery adverts) and peer influence (friend conversations about appearance) predict attitudes towards cosmetic surgery. Specifically, a higher amount of media exposure and friend conservations correlates with more positive attitudes towards cosmetic surgery (Sharp et al. 2014). This suggests that traditional forms of media such as television programmes about cosmetic surgery are a motivating factor in women undergoing cosmetic surgery.

Whilst the role of cosmetic programmes, magazines and advertisements have been investigated as potential influencing factors for consideration of cosmetic surgery, less research has investigated the role of social media, particularly newer forms such as Instagram, on desire for cosmetic surgery. Also, most studies to date have been correlational in nature (e.g., Sarwer et al. 2005; Soest et al. 2006; Markey and Markey 2009; Swami 2009; Furnham and Levitas 2012; Sharp et al. 2014), with not much experimental research being carried out. Further, research has historically focused on attitudes (positive/negative) towards cosmetic surgery, which whilst being influential in deciding behaviour, do not necessarily indicate actual behaviour. Hence, the current study intends to fill this gap by examining the effect of Instagram on desire for cosmetic surgery. It aims to examine whether exposure to young women with facial cosmetic enhancements causes participants to consider undergoing cosmetic surgery, hypothesising that viewing images of females who have undergone cosmetic surgery (compared to a control condition) will lead participants to have an increased desire for cosmetic surgery.

A potential model explaining the effect of social media use (e.g. Instagram) on the desire for cosmetic surgery points toward the mediating role of body dissatisfaction. Studies have found that social media use can impact desire for cosmetic surgery (American Academy of Facial Plastic and Reconstructive Surgery 2013; De Vries et al. 2014). Therefore, we hypothesise that those who use social media more will show a higher desire for cosmetic surgery than those who use it less. Additionally, body dissatisfaction has been found to influence attitudes towards cosmetic surgery (Lee et al. 2009; Markey and Markey 2009). Thus, it is hypothesised that those who have lower appearance satisfaction will have a higher desire for cosmetic surgery than those who are more satisfied with their appearance. Also, social media use has been found to negatively affect body 
satisfaction (Brown and Tiggemann 2016; Holland and Tiggemann 2016). It may be that social media use influences body dissatisfaction, which in turn leads to an increased desire for cosmetic surgery. This study aims to test this mediation model as a mechanism for how social media affects desire for cosmetic surgery among young women.

\section{Method}

\section{Participants and Design}

The study employed a between-subjects design with two levels of the independent variable: cosmetic enhancement condition and travel image condition. An a priori power analysis using G*Power (Faul et al. 2007) indicated that 51 participants were needed in each condition to have $80 \%$ power for detecting a medium sized effect $(d=0.5)$, when employing a 0.05 criterion of statistical significance. We intentionally oversampled in a single wave of data collection via social media, survey distribution websites and the undergraduate psychology programme of a state university in the UK. 118 women aged 18-29 years $\left(M_{\text {age }}=20.71\right.$ years, $S D=2.53$ ) took part in this study. Most of the participants had been a resident in the UK/US for several years, comprising young professionals or university students. They represented a diverse ethnic group (50.9\% White, $25.3 \%$ Asian, $10.1 \%$ Black, $13.5 \%$ Other). Only 4 participants (3.4\%) had previously undergone a cosmetic procedure (facial filler, Botox, microdermabrasion and scar retouching). Participants were randomly allocated to one of the two conditions, resulting in 59 people in the cosmetic enhancement condition and 59 people in the travel image condition (control group). Ethical approval for the present study was granted by the Department of Psychology Ethics Committee. Participants provided written informed consent prior to participation. Compensation was given to participants in the form of course credits (to those recruited via the undergraduate psychology programme) and those who were collected via the social media and survey distribution websites were entered into a raffle prize draw for Amazon vouchers, if they wished. In the debriefing, no participants correctly identified the main study hypothesis or correctly indicated the true aims of the study.

\section{Stimuli}

Pretesting The stimulus images were chosen from a pool of 30 cosmetic enhancement images and 30 travel images. An online survey was conducted by five female raters to determine the images for inclusion in the main study $(M=18.20, S D=0.45)$. Participants were asked to rate the extent to which they think that the person in the picture has had cosmetic enhancements performed to their face $(0=$ strongly disagree, $100=$ strongly agree $)$, the person in the image appeared to be successful $(0=$ not at all successful, $100=$ very successful), and the images reflected material that they would typically see on Instagram $(0=$ not typical at all, $100=$ very typical $)$. The images that scored the highest were selected for use in the main study.

Main Study Two sets of images were constructed for use in this study. The cosmetic enhancement condition comprised 15 images of female faces who had undergone at least one of the procedures commonly reported by young adult women. These include: rhinoplasty, soft tissue fillers, Botox, laser skin resurfacing and microdermabrasion (American Society of Plastic Surgeons 2016). All female targets were in the age range of 18 to 29 years and had a public Instagram account. We specifically targeted Instagram pages which hosted cosmetic images of people. The first picture of primarily their face (frontal picture showing the head and shoulders with adequate illumination and no filters) was chosen. The travel image condition contained 15 images of travel destinations selected from the Internet. Images in both conditions were in colour.

\section{Procedure}

The study was conducted using Qualtrics (Provo, UT), a webbased software, and was advertised as a survey on 'Instagram and Recall'. Participants were informed that the research was investigating whether Instagram use has an effect on the ability to recall details of images and if personal characteristics influence this relationship. At the beginning of the study, participants answered questions about their use of social networking sites. They were asked whether they have an Instagram account, how much time they spend on Instagram per day (less than an hour, 1-3 h, 4-7 h, $8 \mathrm{~h}+$ ), and the number of accounts they follow (less than 100, 101-300, 301-500, 501$700,701-900,901+)$. Answers to these questions were positively correlated (Spearman's $r h o=.27, p=.004$ ); hence we summed them together, with a higher score indicating more social media use.

Participants were then shown in a random order a series of 15 Instagram images (approximately $750 \times 750$ pixels) of similarly aged women who have undergone cosmetic enhancements to their faces (or images of travel). They were told that they could view each image for up to 5 min and click the next button when they were done. Following the image viewing task, they completed several self-report scales assessing their dissatisfaction with their appearance, their mood, and their attitudes towards cosmetic enhancement. The sequence of the scales was fixed, with the ACSS scale always appearing last as the main dependant measure.

Appearance Satisfaction Participants completed a visual analogue scale (VAS), measuring their satisfaction with their appearance after seeing the images of the women (or images of 
travel). The scale consisted of a 100-point horizontal line with endpoints labelled as 'not at all' and 'extremely'. Participants were told to indicate how they are feeling about their appearance "right now" by moving the slider to a point on the line. Lower scores indicate lower appearance satisfaction. VAS have been shown to reliably assess body dissatisfaction before and after image viewing with internal reliability for the measure reported as $\alpha=.86$ (Tiggemann and Zaccardo 2015). For the current sample, internal reliability was $\alpha=.79$.

Mood Participants completed VAS measuring how negative, depressed and anxious they felt after seeing the images of the women (or images of travel). Higher scores indicate a more negative mood, more depression, and more anxiety. VAS have been shown to reliably assess mood before and after image viewing with internal reliability for the measure reported as $\alpha=.75$ (Tiggemann and Zaccardo 2015). Internal reliability for the current sample was acceptable at $\alpha=.79$.

Consideration of Cosmetic Surgery Participants completed the 'Consider' subscale of the Acceptance of Cosmetic Surgery Scale (ACSS; Henderson-King and Henderson-King 2005). The ACSS consists of 15 items using a 7-point Likert scale and measures attitudinal dispositions towards cosmetic surgery. The 'Consider' subscale includes 5 items that measure the self-reported likelihood of participants having cosmetic surgery in the future. Questions are rated on a 7-point Likert scale $(1=$ strongly disagree, $7=$ strongly agree $)$ and include items such as, "In the future, I could end up having some kind of cosmetic surgery". Higher scores indicate greater consideration of cosmetic surgery. In the present study, composite scores were created by summing participants' responses to all 5 questions. Participants were presented with a list of the 5 most popular facial cosmetic procedures that young adult women (18-29 years) are likely to get, and asked to consider how likely they would be to undergo any of those procedures. This list was taken from the American Society of Plastic Surgeons website (see ASPS 2016). As financial expense could potentially be a prohibitive factor, participants were asked to respond as if money was no object. The ACSS has good internal reliability $(\alpha=.88)$, good test-retest reliability $(\alpha=.74)$, and good construct validity (Henderson-King and Henderson-King 2005). For the current sample, Cronbach's alpha for the 'Consider' subscale was $\alpha=.93$. The scale had evidence of concurrent and construct validity.

Finally, participants completed a questionnaire consisting of multiple-choice questions ostensibly intended to measure their recall of the images (e.g., "What capital city was pictured in one of the images? Answer options: Cardiff, Dublin, London." "What colour lipstick was one of the women in the images wearing? Answer options: red, purple, orange"). Given that this filler task mainly served to mask the true aims of the study, answers were not considered in further analyses.

\section{Results}

All statistical analyses were conducted using IBM SPSS Statistics 22. We first investigated the effect of condition on the main dependent measure, by testing whether the viewing of women who had undergone cosmetic surgery (vs. control condition) leads participants to have an increased desire for cosmetic surgery. In order to control for the effect of negative mood, depression, anxiety, and age, an analysis of covariance (ANCOVA) was conducted. Results showed a marginally significant difference between the cosmetically enhanced image condition and the travel image condition, $F(1,88)=3.67$, $p=.059, \eta_{\mathrm{p}}{ }^{2}=.04$. As such, participants who had viewed images of cosmetically enhanced females showed a tendency for an increased desire for cosmetic surgery $(M=21.16, S D=$ 9.33) compared to participants who saw images of travel $(M=$ $17.59, S D=8.96)$. There were no significant effects of negative $\operatorname{mood} F(1,88)=1.95, p=.166, \eta_{\mathrm{p}}{ }^{2}=.02$, depression $F(1$, $88)=0.69, p=.409, \eta_{\mathrm{p}}{ }^{2}=.01$, or anxiety $F(1,88)=1.31$, $p=.255, \eta_{\mathrm{p}}{ }^{2}=.04$, on participants' desire for cosmetic surgery. As such, viewing images of females who had undergone cosmetic enhancement was unaffected by these personal trait variables.

To explore the prediction that the desire for cosmetic surgery would be mediated by lower appearance satisfaction due to social media use, we conducted a series of regression analyses following Baron and Kenny's (1986) approach. As shown in Fig. 1, social media use significantly predicted desire for cosmetic surgery; total effect: $t(1)=3.50, \beta=1.55$, $p=.001,95 \%$ CI $[.67,2.42]$. The more participants used social media in their everyday lives, the more likely they were to consider cosmetic surgery. There was also a marginally significant trend for social media use to predict body dissatisfaction, $t(1)=-1.95, \beta=-2.20, p=.053,95 \%$ CI $[-4.43, .03]$. Additionally, a significant negative relationship between body dissatisfaction and desire for cosmetic surgery was observed, $t(1)=-2.49, \beta=-.092, p=.014,95 \%$ CI $[-.16,-.02]$. The less satisfied participants were with their appearance, the more likely they were to consider cosmetic surgery. The predictive effect of social media on participants' desire for cosmetic surgery remained significant when controlling for body dissatisfaction; direct effect: $t(2)=3.13, \beta=1.39, p=.002,95 \% \mathrm{CI}$ $[.51,2.27]$. A bootstrapping analysis following Preacher and Hayes's (2008) approach (using the PROCESS macro, computed for each 10,000 bootstrapped samples) revealed that the $95 \%$ confidence $[-.01, .52]$ interval for the indirect effect (effect size $=.16$ ) included zero. A Sobel test was conducted and confirmed that the mediation was non-significant $(z=1.30$, $p=.193$ ). Hence, body dissatisfaction failed to act as a significant mediator in the model.

Finally, we examined whether participants' social media use and body dissatisfaction moderate the effect of condition (cosmetic, travel) on their desire for cosmetic surgery. For this, 
Fig. 1 Mediation model for the effect of social media use on desire for cosmetic surgery via body dissatisfaction. Values for the indirect path (i.e., when controlling for the mediator) are shown in parenthesis

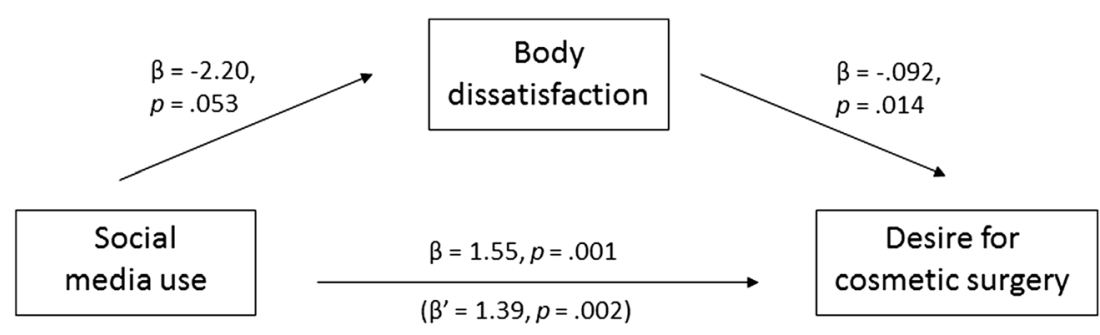

ACSS scores were submitted to a Condition $(1=$ cosmetic enhancement images, $-1=$ travel images) $\mathrm{x}$ Social Media Use or Body Dissatisfaction regression analysis. Results revealed that only social media use, $t(1)=2.00, \beta=3.02$, $p=.048,95 \%$ CI $[.00, .60]$, but not body dissatisfaction, $t(1)=1.46, \beta=0.02, p=.148,95 \%$ CI $[-.01, .05]$, moderated the effect of condition on desire for cosmetic surgery. Analyses conducted separately for each experimental condition showed that social media use, $t(2)=3.48, \beta=1.98$, $p=.001,95 \%$ CI $[.84,3.11]$ was more predictive of the desire for cosmetic surgery than body dissatisfaction, $t(2)=-1.63$, $\beta=-.078, p=.108,95 \% \mathrm{CI}[-.17, .02]$, for participants in the cosmetic enhancement condition. In comparison, neither social media use, $t(2)=.851, \beta=.592, p=.398,95 \% \mathrm{CI}$ $[-.80,1.98]$, nor body dissatisfaction, $t(2)=-1.34, \beta=$ $-.073, p=.187,95 \%$ CI $[-.18, .04]$, significantly predicted desire for cosmetic surgery for participants in the travel condition. This would suggest that exposure to cosmetic images makes participants particularly likely to desire cosmetic surgery when they use social media a lot.

\section{Discussion}

The current study aimed to explore whether exposure to images with facial cosmetic enhancements increases the desire for cosmetic surgery. Furthermore, we planned to test the mediation model that social media use leads to body dissatisfaction which in turn makes people desire cosmetic surgery. The results showed that viewing images of cosmetically enhanced females had a marginally significant effect on desire for cosmetic surgery. These results therefore partially supported the hypothesis that cosmetic enhancement images (compared to a control condition) induce a desire for cosmetic surgery. Moreover, those who were frequent social media users and who were less satisfied with their appearance were more likely to consider cosmetic surgery in the future. Although higher social media use did not lower appearance satisfaction per se, participants who saw cosmetically enhanced females (vs. travel images) and who used social media a lot were significantly more likely to desire cosmetic surgery. Lastly, the results show that the relationship between social media use and desire for cosmetic surgery was not mediated by body dissatisfaction. Social media use was a stronger predictor of a participants' desire for cosmetic surgery than body dissatisfaction. These findings therefore suggest that viewing images of females with cosmetic enhancements can have an effect on young women's desire for cosmetic surgery, especially if they frequently spend a significant amount of time on social media, follow many accounts and are less satisfied with their appearance.

The present results are in line with previous research by showing that those who use social media more (De Vries et al. 2014) and are dissatisfied with their appearance (Lee et al. 2009; Markey and Markey 2009) are more likely to consider cosmetic surgery. However, it should be noted that the desire for cosmetic surgery between participants in the cosmetic enhancement and travel condition was only marginally significant. Psychological movements placing an emphasis on the acceptance of one's body, such as body compassion (Altman et al. 2017a) and the acceptance and commitment approach (Hayes et al. 2012) have gained popularity as treatments for body image dissatisfaction (Hill et al. 2015; Altman et al. 2017b). These movements encourage one to shift their view of the body from one of judgement and comparison to societal ideals, to one of openness and curiosity, embracing the appearance, state of health, and functioning of one's body exactly as it is in the present (Altman et al. 2017b). Similarly, in popular culture there has been a rise in movements placing an emphasis on self-love and acceptance, such as the 'body positive movement' and campaigns seeing popular high-street fashion brands no longer digitally retouching photos of their models (The Independent 2017; Tan 2018). Young women are being encouraged to embrace and accept the way that they look, and in turn, this could make them less likely to want to undergo cosmetic procedures to change the way they look. For example, the number of cosmetic procedures conducted in 2016 fell $40 \%$ from a record-breaking high in 2015 (British Association of Aesthetic Plastic Surgeons 2017). In this way, the decreased societal pressure to conform to an idealized beauty standard may be encouraging women away from having cosmetic surgery (Henderson-King and Brooks 2009).

The present study tested a mediation model proposing that increased social media use leads to dissatisfaction with one's appearance which in turn induces a desire for cosmetic surgery. Previous research has found that social network site use can impact desire for cosmetic surgery (De Vries et al. 2014), body dissatisfaction influences attitudes towards cosmetic 
surgery (Lee et al. 2009; Markey and Markey 2009), and social media use negatively affects body satisfaction (Brown and Tiggemann 2016; Holland and Tiggemann 2016). In this study, the mediating role of body dissatisfaction was not supported. This may be because previous research was correlational, suggesting an increased likelihood that body dissatisfaction is influencing desire for cosmetic surgery but not a causational influence. Therefore, it could be the case that some other unknown factors are underlying this relationship. An alternative mediator may be appearance investment. De Vries et al. (2014) showed that among adolescents more frequent social network site use predicts increases in appearance investment, which is related to an increased desire to undergo cosmetic surgery. Similarly, Sarwer et al. (2005) found that greater psychological investment in physical appearance predicted more favourable attitudes towards cosmetic surgery. Thus, social media could be influencing desire for cosmetic surgery via appearance investment. As such, the appearance pressures exerted by social media may lead people who are more invested in their appearance to engage in appearancechanging strategies such as cosmetic surgery. However, it is also possible that body dissatisfaction has no influence on the desire for cosmetic surgery. According to some researchers, no differences exist between satisfied and dissatisfied people in their desire to undergo cosmetic surgery (Frederick et al. 2007). Similarly, dissatisfaction may be more a function of age. As individuals get older their dissatisfaction with their appearance decreases and thus their interest in cosmetic surgery (Rauste-von Wright 1988). The relationship between dissatisfaction with one's appearance and interest in cosmetic surgery is complex, and further research is needed to clarify the role that dissatisfaction plays in the motivation to undergo cosmetic surgery.

Nonetheless, the findings of this study are in line with the Tripartite Influence Model (Thompson et al. 1999) which argues that beauty ideals are reinforced and transmitted by primary sociocultural influences, i.e. peers, parents and the media. According to this model, internalisation of appearance ideals and appearance comparison are the two attributes which mediate the influence of sociocultural factors. As such, it is possible that the young women in this study found themselves to be lacking in (internalised and stereotypical) beauty ideals and when comparing themselves to the female targets in the images became dissatisfied. This increased dissatisfaction may have led to greater engagement with appearancechanging strategies such as cosmetic surgery. Empirical support for this assumption comes from research showing that more media exposure and friend conversations about appearance can positively influence women's attitudes towards cosmetic surgery (Sharp et al. 2014). Also, media exposure and friend conversations indirectly affect cosmetic surgery attitudes through the internalisation of appearance ideals (Sharp et al. 2014). In the present study, participants may therefore have internalized the beauty ideals surrounding cosmetic enhancements as portrayed by the women in the images, which made them more likely to consider cosmetic surgery.

Although these findings contribute to the greater understanding of the causal role that social media plays in young women's consideration of cosmetic surgery, there were some limitations to this study. Body Mass Index (BMI) could have been controlled as a covariate as it has been shown to influence decisions to undergo cosmetic surgery (Henderson-King and Brooks 2009; Swami 2009); thus the results of this study could be very different with the introduction of this variable. The sample was fairly homogenous as most participants were university students, limiting the generalizability of these findings. Similarly, as the sample was comprised of women in late adolescence $\left(M_{\text {age }}=20.71\right.$ years $)$ - a time when one of the fundamental developmental tasks includes accepting one's body and appearance (Altabe and Thompson 1993) - there may be a significant focus on appearance during this period of life, which may not necessarily be the case in later life. Hence, the results of this particular sample may represent a period in life when body acceptance and satisfaction are a significant issue of concern, limiting the generalization of these findings to young womanhood.

The effect of social media on desire for cosmetic surgery could also be exaggerated amongst this particular sample as young women are more likely to use social media (Office for National Statistics 2017) and be concerned about their looks (Lawler and Nixon 2011). Furthermore, the participants only had brief exposure to the images which is unlike how they would interact with these images in everyday life. We also must distinguish between the intention to undergo cosmetic surgery (as measured by the ACSS) and actual behaviour. Whilst this study shows that on account of viewing images of cosmetically enhanced females, participants report greater desire to have cosmetic surgery, it does not necessarily follow that they will in fact undergo cosmetic procedures. The present results point towards greater intentions, which may or may not manifest in subsequent behaviour.

The present study constitutes an important first step in determining the causal effects of media exposure on young women's desire for cosmetic surgery. Future research is needed to examine other contributing factors for understanding the psychosocial motivations of young women who undergo cosmetic surgery. Considering previous research and the limitations of this study, future research should incorporate a longitudinal data collection design. In this context, participants may view images of individuals who have had cosmetic enhancements over an extended period of time, sampling a more ethnically diverse population, to provide more valid insights into the role played by social media. Sampling participants who have already undergone cosmetic surgery and assessing the extent to which social media influenced their decision may prove similarly valuable. 


\section{Practical Implications}

The results of this study provide support for the introduction of psychological screenings of cosmetic surgery patients and can contribute a positive change for the community and its patients. By understanding how social media impacts the desire for cosmetic surgery, the outcomes of the present work can be particularly influential for women who have body image concerns and spend more time on social media sites. As a result, screening measures can be introduced into cosmetic surgery clinics and practices that better assess clients' motivations for the surgery and their psychological functioning. If their motivations are based on looking like someone they have seen on social media, it is unlikely that cosmetic treatments will have positive outcomes (Lee et al. 2009). Implementation of successful screening tools would contribute to better identification of patients who are likely to benefit the most from the procedure, thereby avoiding engaging patients in procedures that they may not be happy with. The findings from this study further suggest that increased media literacy training could be advantageous for young women. By alerting these women to the influence that online images can have on their behaviours and body image, we can improve their psycho-social functioning. For example, it has been shown that media literacy training can decrease women's favourable attitudes towards elective cosmetic surgery and increase self-esteem (Khazir et al. 2016). Implementing media literacy training in universities and work places could therefore be a way to reduce the negative effects that viewing images of cosmetically enhanced females on social media has on young women's body image.

\section{Compliance with Ethical Standards}

Conflict of Interest On behalf of all authors, the corresponding author states that there is no conflict of interest.

Open Access This article is distributed under the terms of the Creative Commons Attribution 4.0 International License (http:// creativecommons.org/licenses/by/4.0/), which permits unrestricted use, distribution, and reproduction in any medium, provided you give appropriate credit to the original author(s) and the source, provide a link to the Creative Commons license, and indicate if changes were made.

\section{References}

Altabe, M., \& Thompson, J. K. (1993). Body image changes during early adulthood. International Journal of Eating Disorders, 13(3), 323328.

Altman, J. K., Linfield, K., Salmon, P. G., \& Beacham, A. O. (2017a). The body compassion scale: Development and initial validation. Journal of Health Psychology., 1359105317718924.
Altman, J. K., Zimmaro, L. A., \& Woodruff-Borden, J. (2017b). Targeting body compassion in the treatment of body dissatisfaction: A case study. Clinical Case Studies, 16(6), 431-445. https://doi.org/ 10.1177/1534650117731155.

American Academy of Facial Plastic and Reconstructive Surgery. (2013). Retrieved from https://www.prnewswire.com/news-releases/newsurvey-finds-social-media-is-a-major-influence-on-electivesurgery-191992411.html. Accessed 12 Apr 2019.

American Psychiatric Association. (2013). Diagnostic and statistical manual of mental disorders (5th ed.). Arlington: American Psychiatric Publishing, Inc.

American Society for Aesthetic Plastic Surgery. (2017). Retrieved from https://www.surgery.org/media/statistics. Accessed 12 Apr 2019.

American Society of Plastic Surgeons. (2016). Retrieved from https:// www.plasticsurgery.org/news/plastic-surgery-statistics. Accessed 12 Apr 2019.

American Society of Plastic Surgeons. (2018). Retrieved from https:// www.plasticsurgery.org/news/blog/whats-the-difference-betweenreconstructive-and-cosmetic-procedures. Accessed 12 Apr 2019.

Baron, R. M., \& Kenny, D. A. (1986). The moderator-mediator variable distinction in social psychological research: Conceptual, strategic, and statistical considerations. Journal of Personality and Social Psychology, 51(6), 1173-1182. https://doi.org/10.1037/0022-3514. 51.6.1173.

Blascovich, J., \& Tomaka, J. (1991). Measures of self-esteem. In J. P. Robinson, P. R. Shaver, \& L. S. Wrightsman (Eds.), Measures of social psychological attitudes, Vol. 1. Measures of personality and social psychological attitudes (pp. 115-160). San Diego: Academic Press. https://doi.org/10.1016/B978-0-12-590241-0.50008-3.

British Association of Aesthetic Plastic Surgeons. (2017). The Bust Boom Busts. Retrieved October $8^{\text {th }}, 2017$ from https://baaps.org.uk/media/ press_releases/29/the_bust_boom busts. Accessed 12 Apr 2019.

Brown, Z., \& Tiggemann, M. (2016). Attractive celebrity and peer images on Instagram: Effect on women's mood and body image. Body Image, 19, 37-43. https://doi.org/10.1016/j. bodyim.2016.08.007.

Brown, A., Furnham, A., Glanville, L., \& Swami, V. (2007). Factors that affect the likelihood of undergoing cosmetic surgery. Aesthetic Surgery Journal, 27(5), 501-508. https://doi.org/10.1016/j.asj. 2007.06.004.

Cafri, G., Yamamiya, Y., Brannick, M., \& Thompson, J. K. (2005). The influence of sociocultural factors on body image: A meta-analysis. Clinical Psychology: Science and Practice, 12, 421-433. https://doi. org/10.1093/clipsy/bpi053.

Castle, D. J., Honigman, R. J., \& Phillips, K. A. (2002). Does cosmetic surgery improve psychosocial wellbeing? Medical Journal of Australia, 176(12), 601-603.

Crerand, C. E., Franklin, M. E., \& Sarwer, D. B. (2006). Body dysmorphic disorder and cosmetic surgery. Plastic and Reconstructive Surgery, 118(7), 167-180. https://doi.org/10.1097/01.prs. 0000242500.28431 .24 .

Davison, K. K., \& Birch, L. L. (2001). Weight status, parent reaction, and self-concept in five-year-old girls. Pediatrics, 107(1), 46-53. https:// doi.org/10.1542/peds.107.1.46.

De Vries, D. A., Peter, J., Nikken, P., \& de Graaf, H. (2014). The effect of social network site use on appearance investment and desire for cosmetic surgery among adolescent boys and girls. Sex Roles, 71(9-10), 283-295. https://doi.org/10.1007/s11199014-0412-6.

Fardouly, J., \& Vartanian, L. R. (2016). Social media and body image concerns: Current research and future directions. Current Opinion in Psychology, 9, 1-5. https://doi.org/10.1016/j.copsyc.2015.09.005.

Faul, F., Erdfelder, E., Lang, A. G., \& Buchner, A. (2007). G* Power 3: A flexible statistical power analysis program for the social, behavioral, and biomedical sciences. Behavior Research Methods, 39(2), 175191. 
Frederick, D. A., Lever, J., \& Peplau, L. A. (2007). Interest in cosmetic surgery and body image: Views of men and women across the lifespan. Plastic and Reconstructive Surgery, 120(5), 1407-1415. https://doi.org/10.1097/01.prs.0000279375.26157.64.

Furnham, A., \& Levitas, J. (2012). Factors that motivate people to undergo cosmetic surgery. Canadian Journal of Plastic Surgery, 20(4), 47-50. https://doi.org/10.1177/229255031202000406.

Groesz, L. M., Levine, M. P., \& Murnen, S. K. (2002). The effect of experimental presentation of thin media images on body satisfaction: A meta-analytic review. International Journal of Eating Disorders, 31(1), 1-16. https://doi.org/10.1002/eat. 10005 .

Grogan, S. (2008). Body image: Understanding body dissatisfaction in men, women and children (2nd ed.). New York: Routledge/Taylor \& Francis Group.

Hayes, S. C., Strosahl, K. D., \& Wilson, K. G. (2012). Acceptance and commitment therapy: The process and practice of mindful change (2nd ed.). New York: Guilford Press.

Henderson-King, D., \& Brooks, K. D. (2009). Materialism, sociocultural appearance messages, and paternal attitudes predict college women's attitudes about cosmetic surgery. Psychology of Women Quarterly, 33(1), 133-142. https://doi.org/10.1111/j. 1471-6402.2008.01480.x.

Henderson-King, D., \& Henderson-King, E. (2005). Acceptance of cosmetic surgery: Scale development and validation. Body Image, 2(2), 137-149. https://doi.org/10.1016/j.bodyim.2005.03.003.

Hill, M. L., Masuda, A., Moore, M., \& Twohig, M. P. (2015). Acceptance and commitment therapy for individuals with problematic emotional eating: A case-series study. Clinical Case Studies, 14(2), 141-154. https://doi.org/10.1177/1534650114547429.

Holland, G., \& Tiggemann, M. (2016). A systematic review of the impact of the use of social networking sites on body image and disordered eating outcomes. Body Image, 17, 100-110. https://doi.org/10.1016/ j.bodyim.2016.02.008.

Jackson, A. C., Dowling, N. A., Honigman, R. J., Francis, K. L., \& Kalus, A. M. (2012). The experience of teasing in elective cosmetic surgery patients. Behavioral Medicine, 38(4), 129-137. https://doi.org/10. 1080/08964289.2012.703976.

Javo, I. M., \& Sørlie, T. (2010). Psychosocial characteristics of young Norwegian women interested in liposuction, breast augmentation, rhinoplasty, and abdominoplasty: A population-based study. Plastic and Reconstructive Surgery, 125(5), 1536-1543. https://doi.org/10. 1097/PRS.0b013e3181d5135a.

Khazir, Z., Dehdari, T., Majdabad, M. M., \& Tehrani, S. P. (2016). Psychological aspects of cosmetic surgery among females: A media literacy training intervention. Global Journal of Health Science, 8(2), 35-45. https://doi.org/10.5539/gjhs.v8n2p35.

Lawler, M., \& Nixon, E. (2011). Body dissatisfaction among adolescent boys and girls: The effects of body mass, peer appearance culture and internalization of appearance ideals. Journal of Youth and Adolescence, 40(1), 59-71. https://doi.org/10.1007/s10964-0099500-2.

Lee, H. H., Damhorst, M. L., \& Paff Ogle, J. (2009). Body satisfaction and attitude theory: Linkages with normative compliance and behaviors undertaken to change the body. Family and Consumer Sciences Research Journal, 37(4), 466-488. https://doi.org/10. 1177/1077727X09333165.

Markey, C. N., \& Markey, P. M. (2005). Relations between body image and dieting behaviors: An examination of gender differences. Sex Roles, 53(7-8), 519-530. https://doi.org/10. 1007/s11199-005-7139-3.

Markey, C. N., \& Markey, P. M. (2009). Correlates of young women's interest in obtaining cosmetic surgery. Sex Roles, 61(3-4), 158-166. https://doi.org/10.1007/s11199-009-9625-5.

Mulkens, S., Bos, A. E., Uleman, R., Muris, P., Mayer, B., \& Velthuis, P. (2012). Psychopathology symptoms in a sample of female cosmetic surgery patients. Journal of Plastic, Reconstructive \& Aesthetic Surgery, 65(3), 321-327. https:// doi.org/10.1016/j.bjps.2017.09.011.

Office for National Statistics. (2017). Retrieved from https://www.ons. gov.uk/peoplepopulationandcommunity/householdcharacteristics/ homeinternetandsocialmediausage/bulletins/ internetaccesshouseholdsandindividuals/2017. Accessed 12 Apr 2019.

Pempek, T. A., Yermolayeva, Y. A., \& Calvert, S. L. (2009). College students' social networking experiences on Facebook. Journal of Applied Developmental Psychology, 30, 227-238. https://doi.org/ 10.1016/j.appdev.2008.12.010.

Pertschuk, M. J., Sarwer, D. B., Wadden, T. A., \& Whitaker, L. A. (1998), Body image dissatisfaction in male cosmetic surgery patients. Aesthetic Plastic Surgery, 22(1), 20-24. https://doi.org/10.1007/ s002669900160.

Preacher, K. J., \& Hayes, A. F. (2008). Asymptotic and resampling strategies for assessing and comparing indirect effects in multiple mediator models. Behavior Research Methods, 40(3), 879-891.

Rauste-von Wright, M. (1988). Body image satisfaction in adolescent girls and boys: A longitudinal study. Journal of Youth and Adolescence, 18(1), 71-83. https://doi.org/10.1007/ BF02139247.

Ringrose, J. (2011). Are you sexy, flirty or a slut? Exploring "sexualization" and how teen girls perform/negotiate digital sexual identity on social networking sites. In R. Gill \& C. Scharff (Eds.), New femininities: Postfeminism, neoliberalism and subjectivity (pp. 99-116). London: Palgrave.

Royal Society for Public Health (2017). \#StatusofMind: Social media and young people's mental health and wellbeing. Retrieved $21^{\text {st }}$ November, 2017 from https://www.rsph.org.uk/uploads/assets/ uploaded/0a21d70e-33c6-4fd7-8aadc6166cfb2055.pdf. Accessed 12 Apr 2019.

Sarwer, D. B., Cash, T. F., Magee, L., Williams, E. F., Thompson, J. K., Roehrig, M., ... \& Anderson, D. A. (2005). Female college students and cosmetic surgery: An investigation of experiences, attitudes, and body image. Plastic and Reconstructive Surgery, 115(3), 931-938.

Sharp, A. C. (2018). The Relationship Between Body Dissatisfaction and Cosmetic Enhancement Surgery (Doctoral dissertation). Walden University, Minneapolis, Minnesota.

Sharp, G., Tiggemann, M., \& Mattiske, J. (2014). The role of media and peer influences in Australian women's attitudes towards cosmetic surgery. Body Image, 11(4), 482-487. https://doi.org/10.1016/j. bodyim.2014.07.009.

Soest, T., Kvalem, I. L., Skolleborg, K. C., \& Roald, H. E. (2006). Psychosocial factors predicting the motivation to undergo cosmetic surgery. Plastic and Reconstructive Surgery, 117(1), 51-62. https:// doi.org/10.1097/01.prs.0000194902.89912.f1.

Soest, T., Kvalem, I. L., Roald, H. E., \& Skolleborg, K. C. (2009). The effects of cosmetic surgery on body image, self-esteem, and psychological problems. Journal of Plastic, Reconstructive \& Aesthetic Surgery, 62(10), 1238-1244. https://doi.org/10.1016/j.bjps.2007. 12.093.

Solvi, A. S., Foss, K., von Soest, T., Roald, H. E., Skolleborg, K. C., \& Holte, A. (2010). Motivational factors and psychological processes in cosmetic breast augmentation surgery. Journal of Plastic, Reconstructive \& Aesthetic Surgery, 63(4), 673-680. https://doi. org/10.1016/j.bjps.2009.01.024.

Sorice, S. C., Li, A. Y., Gilstrap, J., Canales, F. L., \& Furnas, H. J. (2017). Social media and the plastic surgery patient. Plastic and Reconstructive Surgery, 140(5), 1047-1056. https://doi.org/10. 1097/PRS.0000000000003769.

Swami, V. (2009). Body appreciation, media influence, and weight status predict consideration of cosmetic surgery among female 
undergraduates. Body Image, 6(4), 315-317. https://doi.org/10. 1016/j.bodyim.2009.07.001.

Swami, V., \& Furnham, A. (2008). The psychology of physical attraction. London: Routledge.

Swami, V., Chamorro-Premuzic, T., Bridges, S., \& Furnham, A. (2009). Acceptance of cosmetic surgery: Personality and individual difference predictors. Body Image, 6, 7-13. https://doi.org/10.1016/j. bodyim.2008.09.004.

Tan, E. (2018). Why missguided mannequins now have stretch marks. Retrieved February $20^{\text {th }}, 2018$ from https://www.campaignlive.co. uk/article/why-missguided-mannequins-stretch-marks/1457489. Accessed 12 Apr 2019.

The Independent (2017). The rise of stretch marks in advertising and why body positivity is winning. Retrieved February $28^{\text {th }}, 2018$ from https://www.independent.co.uk/life-style/fashion/stretch-marks- adverts-fashion-asos-target-body-positive-plus-size-victoriassecret-lonely-lingerie-a7826471.html. Accessed 12 Apr 2019.

Thompson, J. K., Heinberg, L. J., Altabe, M., \& Tantleff-Dunn, S. (1999). Exacting beauty: Theory, assessment, and treatment of body image disturbance. Washington, DC: American Psychological Association. https://doi.org/10.1037/10312-000.

Tiggemann, M., \& Zaccardo, M. (2015). "Exercise to be fit, not skinny": The effect of fitspiration imagery on women's body image. Body Image, 15, 61-67. https://doi.org/10.1016/j.bodyim.2015.06.003.

Publisher's note Springer Nature remains neutral with regard to jurisdictional claims in published maps and institutional affiliations. 